\title{
Synchronous mucinous cystadenoma ovary, leiomyoma uterus and mucinous adenocarcinoma cervix infiltrating into uterine leiomyoma: a rare case report
}

\author{
Gireesha Rawal, Sufian Zaheer*, Amit Kumar Yadav, Neelam Sahani, Indrani Dhawan
}

Department of Pathology, Vardhman Mahavir Medical College and Safdarjung Hospital, New Delhi, India

Received: 30 May 2017

Accepted: 27 June 2017

*Correspondence:

Dr. Sufian Zaheer,

E-mail: sufianzaheer@gmail.com

Copyright: () the author(s), publisher and licensee Medip Academy. This is an open-access article distributed under the terms of the Creative Commons Attribution Non-Commercial License, which permits unrestricted non-commercial use, distribution, and reproduction in any medium, provided the original work is properly cited.

\begin{abstract}
The overall incidence of synchronous female genital tract malignancies is $0.63 \%$. The most frequently observed synchronous neoplasms are those of the ovary together with the endometrium. Cervical and ovarian malignancies are exceedingly rare. We present the case of a female patient who complained of abdominal distention and pain abdomen. A cervical pap smear was performed, and it showed inflammation and atrophic changes. USG abdomen revealed findings consistent with pyometra. Repeated dilatation and curretage for resolving the pyometra was attempted, but it yielded mucinous fluid only. Another USG abdomen was done, which showed a cervical growth. The patient was taken up for staging laparotomy. Per operatively, no growth could be identified in the cervix. However, dense adhesions of the cervix with the bladder were present. A bilateral salpingo-oophorectomy specimen was sent for intraoperative cytology, and showed mucinous cystadenoma, ovary. Further, the completion total hysterectomy specimen was sent for histopathology. Sections showed adenocarcinoma, cervix and leiomyoma, uterus. The cervical adenocarcinoma showed infiltration into the uterine leiomyoma. Thus, we document a very rare case involving a patient who presented with three coexistent tumours involving bilateral ovaries and uterus. To our knowledge, this is the first reported case of the combination. Accurate diagnosis as separate independent primary tumours or as primary tumour associated with its metastasis, and identification the site of origin in secondary tumours has important prognostic implications and is necessary for appropriate staging and treatment.
\end{abstract}

Keywords: Adenocarcinoma, Cystadenoma, Leiomyoma, Mucinous

\section{INTRODUCTION}

The synchronous or metachronous occurrance of multiple primary cancers in the genital tract is well recognized. The overall incidence of synchronous female genital tract malignancies is $0.63 \% .^{1,2}$ The most frequently observed synchronous neoplasms are those of the ovary together with the endometrium. These constitute $40 \%$ of all, and carry a favourable prognosis because of low malignant potential. ${ }^{3}$ Cervical and ovarian malignancies are still rare, and if they occur they have similar histopathology due to direct spread of cervical malignancy to ovary. ${ }^{4}$

An important category of cervical carcinomas that may show ovarian spread is adenocarcinoma and related tumours. We report an extremely rare case of a combination of three synchronous tumours, i.e., mucinous cystadenoma ovary, adenocarcinoma cervix, and leiomyoma uterus showing infiltration by adenocarcinoma cervix. 


\section{CASE REPORT}

A 62 years old female presented with chief complaints of abdominal distention and pain since, 2 weeks. A cervical pap smear was performed, and it showed inflammation and atrophic changes. USG abdomen revealed findings consistent with pyometra. Repeated dilatation and curretage for resolving the pyometra was attempted, but it yielded mucinous fluid only. Another USG abdomen was done, which showed a cervical growth. The patient was taken up for staging laparotomy. Per operatively, no growth could be identified in the cervix. However, dense adhesions of the cervix with the bladder were present. A bilateral salpingo-oophorectomy specimen was sent for intraoperative cytology. Grossly, both the ovaries were enlarged, with capsular external surface. Multiloculated cysts were seen, filled with mucinous fluid. No papillary excrescences or solid areas were present. Scrape cytology smears prepared from both the ovaries showed similar picture. Smears were cellular, showing clusters and monolayered sheets of epithelial cells. These cells showed intracytoplasmic mucin vacoules. Thus, an impression of mucinous cystadenoma, bilateral ovaries was given. Later the specimen was grossed and paraffin sections confirmed the diagnosis of mucinous cystadenoma, bilateral ovaries (Figure 1).

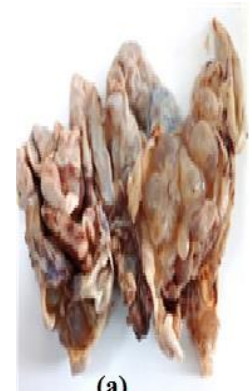

(a)
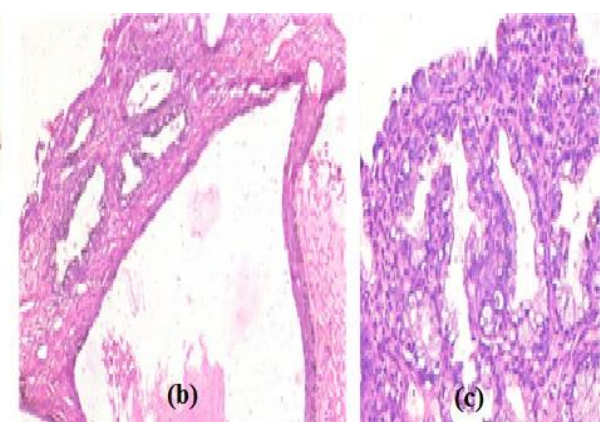

Figure 1: (a) Gross, (b) $\mathrm{H}$ and E section X10, and (c) $H$ and $E$ section X20 showing mucinous cystadenoma ovary.
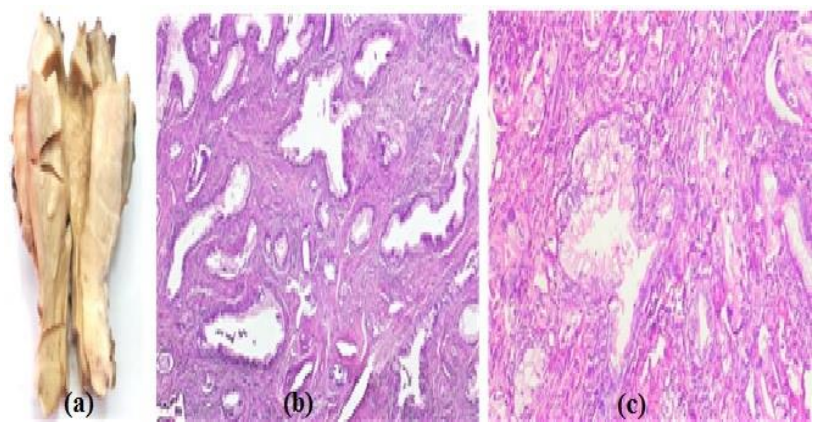

Figure 2: (a) Gross, (b) $\mathrm{H}$ and E section X10, and (c)

$H$ and $E$ section X20 showing mucinous adenocarcinoma, cervix.

Further, the completion total hysterectomy specimen was sent for histopathology. On gross examination, no cervical growth could be identified, though the cervical wall was thickened diffusely, involving all the quadrants, and showed greyish-white discolouration. An intramural fibroid was identified measuring $1 \mathrm{~cm}$ in diameter in the middle uterine segment. Multiple $\mathrm{H}$ and $\mathrm{E}$ sections examined showed a tumour which was composed of tumour cells arranged in glandular pattern. Individual tumour cells were round to oval with moderate amount of cytoplasm and large, vesicular nuclei with prominent nucleoli. Intracellular mucin vacoules could be appreciated. Based on these findings, a diagnosis of moderately differentiated adenocarcinoma, intestinal type, cervix was made. The tumour was involving $>2 / 3 \mathrm{rd}$ of the cervical wall thickness (Figure 2).

In addition, the tumour was involving the lower uterine segment, and infiltrating into the leiomyoma present in the uterus. The tumour was seen to be involving $>2 / 3 \mathrm{rd}$ of the uterine wall thickness. However, endometrial lining showed atrophic changes (Figure 3).
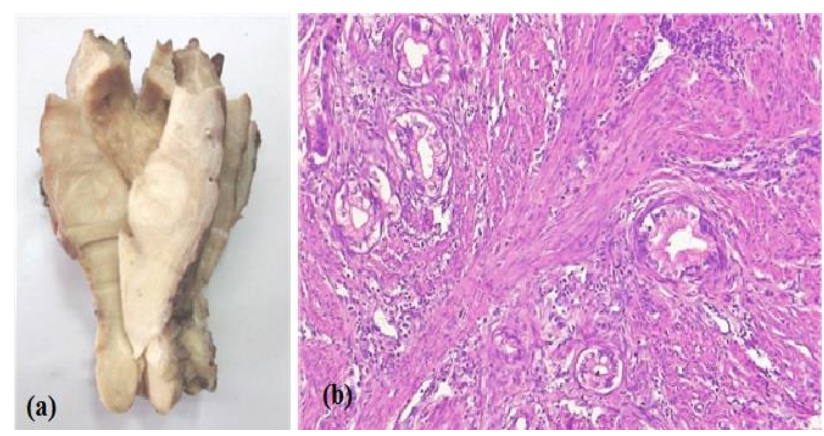

Figure 3: (a) Gross, and (b) $\mathrm{H}$ and E section X20 showing leiomyoma, uterus infiltrated by mucinous adenocarcinoma.

\section{DISCUSSION}

In the current study, we document a very rare case involving a patient who presented with three coexistent tumours involving bilateral ovaries and uterus. To our knowledge, this is the first reported case of the combination.

Simultaneous primary tumours in the ovaries and endometrium can occur, as the surface epithelium of the ovary has the same embryologic derivation as the Müllerian duct. ${ }^{5}$ Therefore, a carcinogenic stimulus may produce similar epithelial proliferations in both structures. ${ }^{6}$ Synchronous and metachronous endometrial and ovarian cancers may be part of familial (hereditary) aggregation of cancers, like mismatch repair genes anomalies, known as Hereditary Non-polyposis colon cancer (HNPCC) and Muir Torre Syndrome and BRCA1 gene mutations resulting in BRCA1 Syndrome. ${ }^{7,8}$

Dioun et al reported the first case of an undetected cervical cancer morcellated at the time of surgery performed for uterine fibroids resulting in widespread 
dissemination of disease and a poor outcome. ${ }^{9}$ This highlights the importance of pap smear prior to hysterectomy, as the same was not done in their case. However, 30-50\% cases may show false negative reports by cytology.

It needs to be differentiated whether synchronous endometrial and ovarian tumours are multifocal or metastatic. However, the overall survival of these patients suggests multifocal rather than metastatic disease ${ }^{10}$, because most of these patients survive without recurrence, a finding that is compatible with stage I endometrial and ovarian carcinomas ${ }^{11-13}$, about a third of the cases (14-29\%) being independent tumours simultaneously involving both sites. ${ }^{14,15}$ These independent primary tumours are of low histologic grade, usually of endometrioid type, and with involvement limited to the endometrium. ${ }^{16}$ Frequently the ovarian tumour is discovered as an incidental finding and diagnosed at an earlier stage because of the symptomatic endometrial tumour. Endometrial carcinoma infiltrating leiomyoma may mimic malignant mixed mullerian tumour.

Accurate diagnosis as separate independent primary tumours or as primary tumour associated with its metastasis, and identification the site of origin in secondary tumours has important prognostic implications and is necessary for appropriate staging and treatment. In daily practice, the diagnosis has relied for many years on assessment of conventional histopathologic parameters. Application of immunohistochemistry and molecular analysis in cases showing overlapping or inconclusive features may facilitate the correct diagnosis.

Funding: No funding sources

Conflict of interest: None declared

Ethical approval: Not required

\section{REFERENCES}

1. Srivastava K, Zahra F. Synchronous primary malignancy of ovary and cervix with different histopathology: a rare presentation. The Internet $\mathbf{J}$ Gynecol Obstetr. 2009;12(2):4.

2. Kambi DP, Mallikarjuna M, Santosh C, Abhishek V. Synchronous malignancies of ovary, fallopian tube and cervix: A rare case. Internat $\mathbf{J}$ Biomedic Advanc Res. 2013;4(9):676-9.

3. Ayhan A, Yalçin OT, Tuncer ZS, Gürgan T, Küçükali T. Synchronous primary malignancies of the female genital tract. Eur J Obstet Gynecol Reprod Biol. 1992;45(1):63-6.

4. Katke RD, Gadekar S, Pagare P. A rare case of carcinoma of ovary with carcinoma of cervix. J Case Reports. 2014;4(1):217-20.
5. Amalinei C. Morphogenesis and differentiation of the female genital tract. Genetic determinism and epithelium-stromal interactions. Rev Med Chir Soc Med Nat Iasi. 2007;111(1):200-9.

6. Matias-Guiu X, Lagarda H, Catasus L, Bussaglia E, Gallardo A, Gras E, et al. Clonality analysis in synchronous or metachronous tumours of the female genital tract. Int J Gynecol Pathol. 2002;21(3):20511.

7. Tavassoli FA, Devilee P. World Health Organization Classification of Tumours, Pathology and genetics. Tumours of the breast and female genital organs. Lyon: IARC Press; 2003.

8. Amalinei C, Balan R, Ivan L, Socolov R, Socolov D, Cotutiu C. Multiple primary malignant neoplasmscase report. Central Europ J Medic. 2006;1(1):87-98.

9. Dioun SM, Soliman PT. Laparoscopic hysterectomy with morcellation for a suspected uterine fibroid resulting in dissemination of cervical adenocarcinoma: A case report. Gynecol Oncol Rep. 2015;12:5-6.

10. Woodruff JD, Julian CG. Multiple malignancy in the upper genital canal. Am J Obstet Gynecol. 1969;103(6):810-22.

11. Eifel P, Hendrickson M, Ross J, Ballon S, Martinez A, Kempson R. Simultaneous presentation of carcinoma involving the ovary and the uterine corpus. Cancer. 1982;50(1):163-70.

12. Ulbright TM, Roth LM. Metastatic and independent cancers of the endometrium and the ovary: a clinicopathologic study of 34 cases. Hum Pathol. 1985;16(1):28-34.

13. Prat J, Matias-Guiu X, Barreto J. Simultaneous carcinoma involving the endometrium and the ovary. A clinicopathologic, immunohistochemical, and DNA flow cytometric study of 18 cases. Cancer. 1991;68(11):2455-9.

14. Klemi PJ, Grönroos M. Endometrioid carcinoma of the ovary. A clinicopathologic, histochemical, and electron microscopic study. Obstet Gynecol. 1979;53(5):572-9.

15. Kline RC, Wharton JT, Atkinson EN, Burke TW, Gershenson DM, Edwards CL. Endometrioid carcinoma of the ovary: retrospective review of 145 cases. Gynecol Oncol. 1990;39(3):337-46.

16. Zaino RJ, Unger ER, Whitney C. Synchronous carcinomas of the uterine corpus and ovary. Gynecol Oncol. 1984;19(3):329-35.

Cite this article as: Rawal G, Zaheer S, Yadav AK, Sahani N, Dhawan I. Synchronous mucinous cystadenoma ovary, leiomyoma uterus and mucinous adenocarcinoma cervix infiltrating into uterine leiomyoma: a rare case report. Int J Reprod Contracept Obstet Gynecol 2017;6:3682-4. 